\title{
Preparing for the MMC interviews: a practical guide for trainees
}

When the Modernising Medical Careers (MMC) programme was proposed in 2003 , it was designed to ensure that 'the end product of the training process, whether a Hospital Doctor or a General Practitioner, should be a high-quality, well-trained and accredited doctor who can deliver the care and treatment to patients in the modern NHS' (Department of Health, 2003). Currently we are at the stage where interviews and recruitment for August 2007 have been completed, and recruitment for 2008 has commenced. It is vital for candidates to have an insight into the interview mechanism. In this article, the structure, types of questions, competencies tested and the methods used for selection such as Objective Structured Clinical Examinations, clinical vignettes, audit and research, teaching and presentation skills are discussed, so that candidates are able to better prepare themselves.

Modernising Medical Careers is a move from timebased to competency-based training. With the change in training scheme throughout the UK, trainee preparation is extremely important. Interviews, the second stage of the recruitment process, also play a pivotal role. But what are these interviews about? What kinds of questions are asked, and how does the selection process work? Familiarity with the structure and methods of the interview may aid potential candidates in preparation. The purpose of this article is to equip candidates with this information. I also hope that the tips included here could be used by trainers to conduct mock interviews in their workplace.

\section{Structure of the specialist training interview}

The minimum standard time allocated for a selection interview is 30 minutes of face-to-face conversation. Some deaneries or units of application may choose to expand on this minimum requirement and others may choose to structure the 30 minutes differently, for example dividing it into three 10-minute or two 15minute slots (MMC Team, 2006). Each slot comprises a station consisting of two interviewers intending to get specific information from the candidate (each of these stations will be described in more detail opposite). The first interviewer will deliver questions and use probes to get the maximum information from the candidate. The second interviewer will record the candidate's responses by making notes. Overall, the candidate may be asked two to four questions per station. The questions are the same for all candidates. When the interview is completed and the candidate leaves the room, the notes will be analysed and the candidate will be scored on a four-point scale.

\section{Question types}

The MMC interviews use structured tools that are designed to measure a variety of skills and abilities using a standard set of questions; this has proven to be a valid method in candidate selection (Schmidt \& Hunter, 1998). The tools for the MMC interviews are a series of questions based directly on person specification, which is derived from a thorough analysis of the skills required for the post in question and is therefore the cornerstone of the selection process. A group of criteria is identified, also based on relevant person specifications, and the questions the candidates are asked are intended to elicit information about these criteria. The deaneries or units of application will score the candidates accordingly (MMC, 2006).

There are two types of questions asked in the interviews:

- behavioural or work samples - based on the belief that past behaviour is the best predictor of future behaviour

- hypothetical or situational - examine how a candidate would respond to hypothetical situations; based on the assumption that a person's intentions are related to their actual behaviour.

Research suggests that both types of questions are valid, although the first is more accurate in judging behaviour than the second (Schmidt \& Hunter, 1998).

\section{Competencies tested}

Six valid competencies which can be legitimately used to select candidates have been determined (Patterson et al, 2005). These are empathy and sensitivity, communication skills, clinical expertise, problem solving, professional integrity and coping with pressure. When it comes to testing competencies, either of the above questioning methods may be used. A candidate should be prepared with a list of examples from their past experience which demonstrate each of the above competencies.

\section{Stations}

Each station is likely to contain at least two of the following:

1. Portfolio

2. Clinical
a. Objective Structured Clinical Examination
b. Clinical vignette

3. Audit and research

4. Teaching

5. Presentation 
F

education \& training

\section{Portfolio}

A candidate's portfolio consists of records of accomplishment and assessments of performance. This has proven useful in the selection process (Sackett et al, 2001) and it is something the interviewers will pay particular attention to. The Royal College of Psychiatrists trainee logbook (http://www.rcpsych.ac.uk/PDF/ LogBook.pdf) is a good format to follow when organising the portfolio. It includes almost all that is essential for a comprehensive evaluation of a trainee. The two sections of training goals and supervisor's feedback are particularly useful for acquiring an overall view of career development (Alwazeer \& Ahmed, 2006).

\section{Clinical}

Objective Structured Clinical Examination

At this station, the candidate will be asked to perform a specific task with a simulator (or the interviewer). This may include one or more of the following: explanation of illness or treatment, history taking, psychopathology. The structured examinations have the advantage of being suitable to test clinical competence using a number of different scenarios in a standardised format (Katona et al, 2000). Their use has recently become widespread, particularly in undergraduate psychiatry exams (Brewin \& Cantwell, 1997), as they have been proven to be reliable and valid (Hodges et al, 1998).

\section{Clinical vignette}

This station tests a candidate's diagnostic skills, clinical application of knowledge and clinical reasoning (Katona et al, 2000). It is fundamental to be able to apply MRCPsych clinical skills by thinking broadly along the lines of the biopsychosocial model, incorporating immediate, short-term and long-term management (Naeem et al, 2003). It is also advisable that a candidate avoid extreme views or flamboyant management ideas (Naeem, 2004).

\section{Audit and research}

This station tests a candidate's knowledge of audit and research. Questions may be general and/or specific to each audit. Some examples:

- 'Is there anything that has changed in your practice recently?'

- 'Tell me about an audit that you have done.'

Some trainees may be able to complete a small research project, either in a senior house officer research post or during their regional day-release course. However, for most senior house officers, participation in formal research is probably an unrealistic aim. Writing up an interesting case report or responding to a published paper is more feasible (Naeem, 2004). It is useful for a candidate to be aware of the importance of research, and of the basic concepts and their application in clinical practice. Some exemplary questions:

- 'How do you organise a research project?'

- 'Which of your publications are you most proud of and why?'
- 'Tell me about a time when you practiced evidencebased medicine.'

Teaching

Questions at this station may include:

- 'What are the qualities of a good teacher?'

- 'What are the points you would consider when preparing to teach medical students?'

\section{Presentation}

Presentations cause anxiety in almost everyone. This station tests a wide range of skills, including communication skills (e.g. the ability to explain complex ideas in a compendious manner and to deal with unpredictable questions). The topics for the presentations in psychiatry are not unusual, however, and there is sufficient time for a candidate to prepare. Examples of topics:

- Why do you want to pursue a career in psychiatry?

- What are the issues affecting psychiatry at the moment?

Note that because slides are a teaching tool, and the point of this test is to assess teaching skills, a candidate should remember that the slides are not to be read but used as a guide. Using diagrams may also be beneficial, but complex flow charts should be avoided.

\section{What are they looking for?}

Recruiters are essentially looking for a confident psychiatric trainee who practices safely. The candidate's level of motivation will also be determined - in other words, it will be assessed whether he or she would be an active participant in the work of the department. In higher levels - Specialty Training level three and above - the recruiters may well be looking at a candidate's attributes that would make them a 'consultant' (if this is the term likely to be used in future).

\section{Requesting feedback}

Requests for feedback should be made in writing (not email) to the unit of application within 2 weeks after the end of the interview process as it will not be provided on the day of the interview. This is due to regulations under the Data Protection Act 1998, which stipulates that feedback must be requested in writing (MMC Team, 2006).

\section{How to prepare}

The specialist training grade trainees are recruited for their personality as well as other attributes, such as their managerial style, leadership qualities, administration skills, proactive attitude, etc. Eventually, final determination comes down to how candidates perform on the 'D-Day' 
and whether he or she is the right person giving the right information at the right time and place.

Early planning, focused training and good career advice are essential. Educational supervisors have a pivotal role in this. Conducting mock interviews with supervisors is very beneficial. While preparing for the interview, candidates are recommended to try a little 'role reversal'. Asking such questions as 'What attributes would you look for if you were on the selection panel?' (Naeem, 2004) can be extremely useful. There are, of course, no 'right' attributes, and consequently, there can be no prefabricated answers. This is not so much an exam as a competition and as such, simply being good is not quite enough. The candidate who is selected must also be better than all the other candidates. Emphasis will be put more on communication skills than on factual knowledge. Most candidates already have what it takes to be successful, but often that potential can be concealed, and this interview process is the method used to reveal that potential. For a successful interview, it is good if candidates can consolidate their knowledge and practice their interview skills.

\section{The 'D-Day'}

Candidates should remember that first impressions are, as in most cases, very important here. The few things they should keep in mind are the dress code, punctuality, and a good night's sleep. The candidate should bring all documentation that has been specified in the invitation to the interview. Without that, a candidate may not be permitted to take part in the interview (MMC Team, 2006). Most importantly, candidates should be prepared for difficult questions, try not to appear nervous and express themselves in a confident manner. The power of body language and voice to build rapport with the interviewer(s) cannot be underestimated, but at the same time, candidates should try to act natural and not be too pedantic about their gestures. My final advice therefore is to be organised and personable.

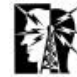

education \& training

\section{Declaration of interest}

None.

\section{References}

ALWAZEER, A. \& AHMED, W. (2006) Specialty RegistrarTraining 2007. Career progression - use of the Modernising Medical CareersTeam trainee logbook. Psychiatric Bulletin, National Health Service. 30, 394 .

BREWIN, J. \& CANTWELL, R. (1997) Implementing the OSCE in Nottingham. Psychiatric Bulletin, 21, 30-32. NAEEM, A., RUTHERFORD, J. \& KENN, C. (2003) The new MRCPsych Part II exam - golden tips on how to pass. DEPARTMENT OF HEALTH (2003) The NAEEM, A. (2004) Psychiatric secrets of Response of the Four UK Health Ministers to the Consultation on Unfinished Business: Proposals for Reform of the Senior House Officer Grade. Department of Health. registrar? Psychiatric Bulletin, 28, 421424.

PATTERSON, F., FERGUSON, E., NORFOLK, T., et al (2005) A new

HODGES, B., REGEHR, G., HANSON, M., et al (1998) Validation of an objective structured clinical examination in psychiatry. Academic Medicine, 73, $910-912$

KATONA, C. TYRER, P. \& SMALLS, J. (2000) Changes to the MRCPsych examinations. Psychiatric Bulletin, 24, 276-278.

MODERNISING MEDICAL CAREERS

(2006) Person Specifications (http:// www.mmc.nhs.uk/pages/specialtiespersonspecs).

MODERNISING MEDICAL CAREERS TEAM (2006) Applicant's Guide to Recruitment and Selection into selection system to recruit general practice registrars: preliminary findings from a validation study. BMJ, 330, 711714

SACKETT, P. R., SCHMITT, N., ELLINGSON, J. E., et al (2001) Highstakes testing in employment, credentialing, and higher education: Prospects in a post-affirmative-action world. American Psychologist, 56, 302-318.

SCHMIDT, F. L. \& HUNTER, J. E. (1998) The validity and utility of selection methods in personnel psychology: practical and theoretical implications of 85 years of research findings. Psychological Bulletin, 124, 262-274.

Hari Kumar Sholinghur Speciality Registrar, North Staffordshire Combined Healthcare NHS Trust, Harplands Hospital, Hilton Road, Stoke onTrent ST4 6TH, email: hsholinghur@doctors.org.uk 